\title{
KUALITAS LINGKUNGAN PERAIRAN PANTAI DI SEKITAR LOKASI TAMBAK PERIKANAN KECAMATAN GEROKGAK KABUPATEN BULELENG
}

\author{
Beny mustofa $^{\left.1^{*}\right)}$, I Wayan Arthana ${ }^{2)}$, Ni Luh Watiniasih ${ }^{3)}$ \\ ${ }^{1)}$ Program Studi Magister Ilmu Lingkungan Universitas Udayana Bali \\ ${ }^{2)}$ Fakultas Kelautan dan Perikanan Universitas Udayana Bali \\ ${ }^{3)}$ Fakultas Matematika dan Ilmu Pengetahuan Alam Universitas Udayana Bali \\ *Email: Benymustofa10@gmail.com
}

\section{ABSTRACT \\ THE QUALITY OF COASTAL WATERS ENVIRONMENT AROUND FISHERIES POND LOCATION IN GEROKGAK DISTRICT, BULELENG REGENCY, BALI}

\begin{abstract}
The purpose of this study was to determine the quality of waters, community structure of phytoplankton and zooplankton around the fishponds waters of Gerokgak Subdistrict. This research was conducted for 2 months, from May to June 2019. There were three sampling locations, namely in Gerokgak, Patas and Sumberkima Villages. The research method used was field research using quantitative analysis of phytoplankton biological indice. The waters condition around the Gerokgak Subdistrict waters was rather polluted, except for the around Sumberkima Village waters. The quality of the waters of Sumberkima Village was better than that of Gerokgak Village and Patas Village waters. Plankton abundance in the waters of Sumberkima Village was slightly low. The highest abundance of plankton in the waters of Patas Village and the lowest in Gerokgak Village waters. The dominant type of plankton was Cyanophyceae (blue-green algae).
\end{abstract}

Keywords: water quality; plankton; species; abundance.

\section{PENDAHULUAN}

Kecamatan Gerokgak merupakan salah satu Kecamatan yang berada di Kabupaten Buleleng yang mengembangkan budidaya ikan dengan karamba jaring apung, budidaya mutiara, tambak udang dan bandeng, budidaya rumput laut, budidaya mina padi, pembenihan serta penangkapan ikan. Potensi perikanan pembudidaya di Kecamatan Gerokgak mengalami perkembangan khususnya pembudidaya ikan dalam keramba jaring apung baik kerapu maupun kakap putih dengan luas potensi yang dimanfaatkan sebesar 66,92 Ha, Luas potensi yang dimanfaatkan untuk budidaya mutiara 110,9 Ha.

Potensi kegiatan pembenihan dan pembesaran ikan bandeng dan kerapu sangat penting sebagai sumber kehidupan masyarakat, maka sehingga diperlukan usaha-usaha mengkaji kelayakan lingkungan agar mencapai budidaya perikanan yang berkelanjutan. Kelayakan lingkungan untuk usaha perikanan yang berkelanjutan dapat diestimasi melalui pengukuran kuantitatif dan kualitatif terhadap biota yang penghuni suatu perairan, sehingga dapat diketahui kualitas perairannya.

Kualitas perairan di sekitar pembenihan udang dan usaha perikanan lainnya, maka perairan tersebut rentan tercemar. Kegiatan perikanan di Kecamatan Gerokgak yang dilakukan oleh masyarakat adalah tambak udang vanname, pengembangan ikan kerapu cantang, pengembangan nener, dan usaha perikanan yang ada di Kecamatan Gerokgak. 
Udang vanname merupakan salah satu jenis udang yang dibudidayakan di Indonesia karena memiliki nilai ekonomis yang cukup tinggi. Penyakit merupakan salah satu kendala yang harus dihadapi oleh pelaku usaha yang bergerak dalam bidang perikanan (Sari, 2015). Dengan banyaknya pelaku usaha perikanan di Kecamatan Gerokgak tidak menutup kemungkinan adanya pencemaran lingkungan yang dihasilkan oleh usaha perikanan di stasiun penelitian yang sudah ditentukan. Oleh karna itu, penelitian tentang lingkungan perairan pantai dilokasi tambak perikanan perlu dilakukan.

\section{METODOLOGI}

\subsection{Lokasi Penelitian}

Penelitian ini dilakukan di 3 desa yaitu Desa Sumberkima, Desa Patas, dan Desa Gerokgak. Ketiga Desa tersebut berada di Kecamatan Gerokgak, Kabupaten Buleleng, Bali. Penelitian ini dilakukan pada tanggal 3 Juli dan 15 Juli 2019. Pemilihan lokasi penelitian di tentukan dengan padatnya kegiatan usaha perikanan yang dapat mempengaruhi kualitas perairanb pantai yang ada di Kecamatan Gerokgak. Peta lokasi penelitian dapat dilihat pada Gambar 1.

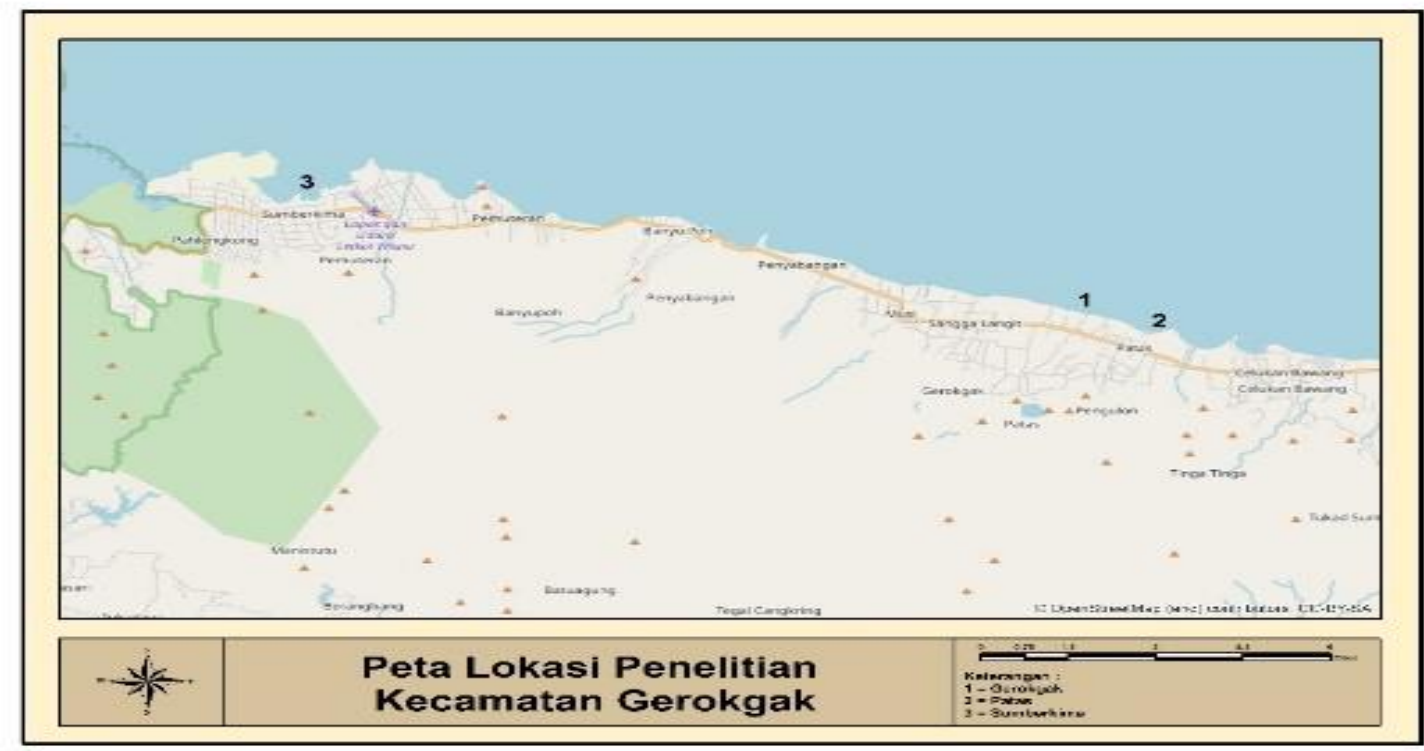

Gambar 1

Peta Penelitian Kecamatan Gerokgak, 1: Gerokgak,2: Patas, 3: Sumberkima.

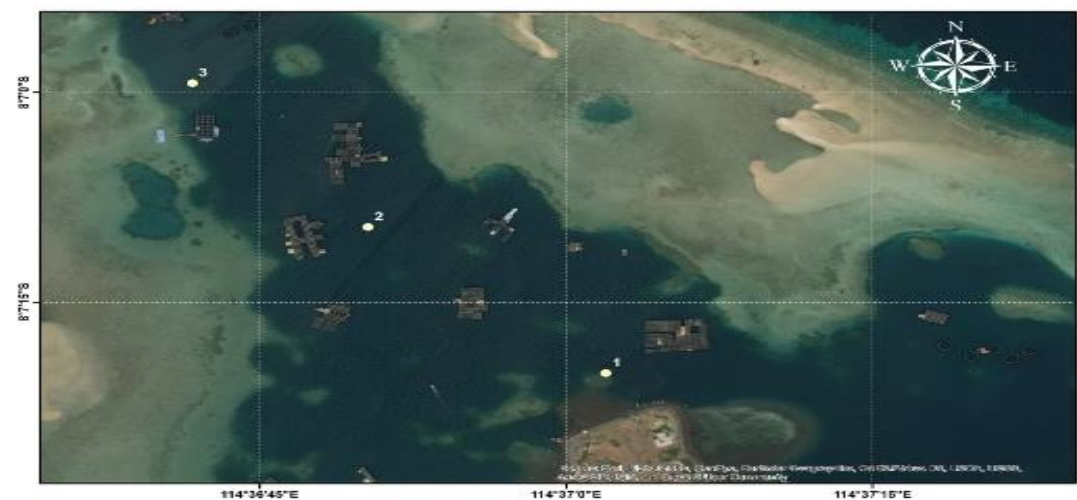

Gambar 2.

Stasiun Penelitian 1 (Desa Sumberkima). Nomer 1,2, dan 3 adalah titik-titik dimana sempel akan diambil 


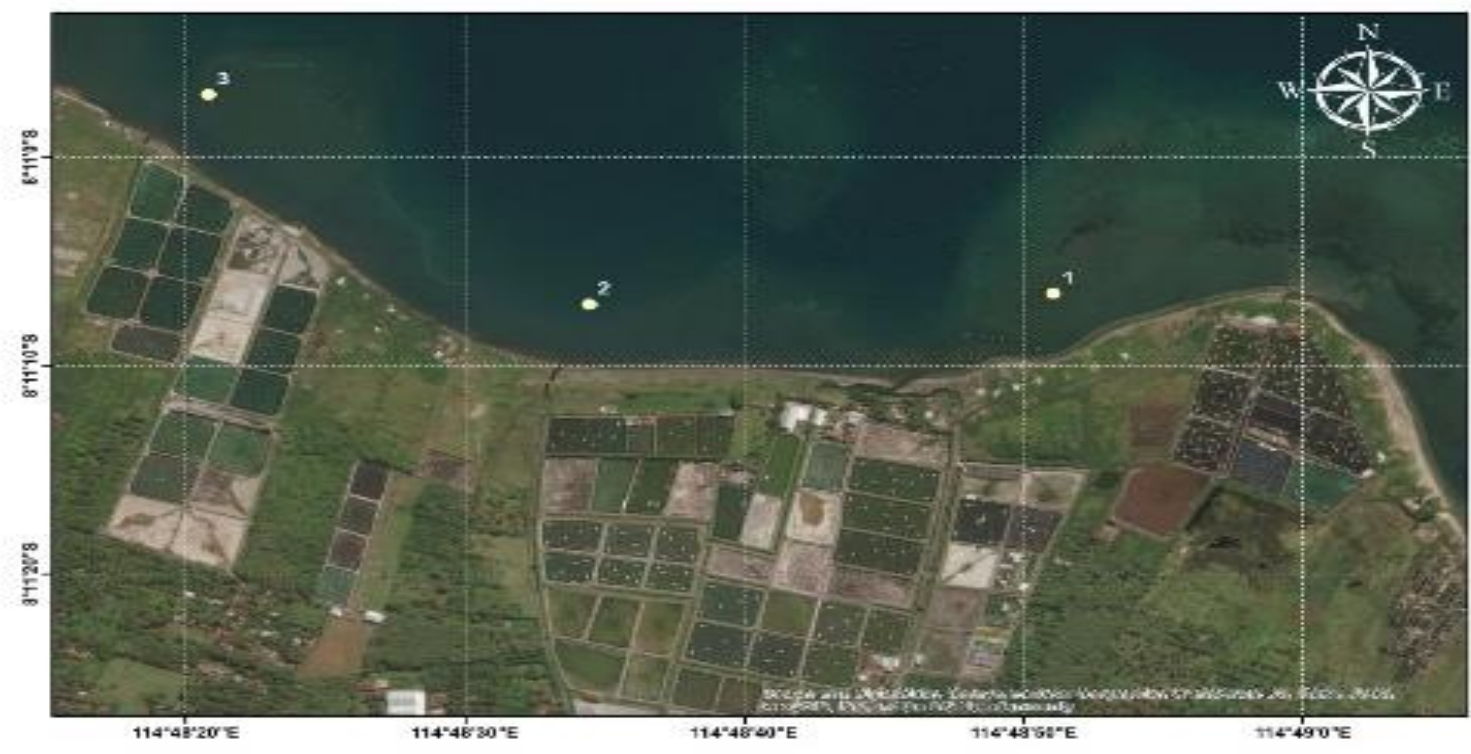

Gambar 3.

Stasiun Penelitian 2 (Desa Patas). Nomer 1, 2, dan 3 adalah titik-titik dimana sempel akan diambil.

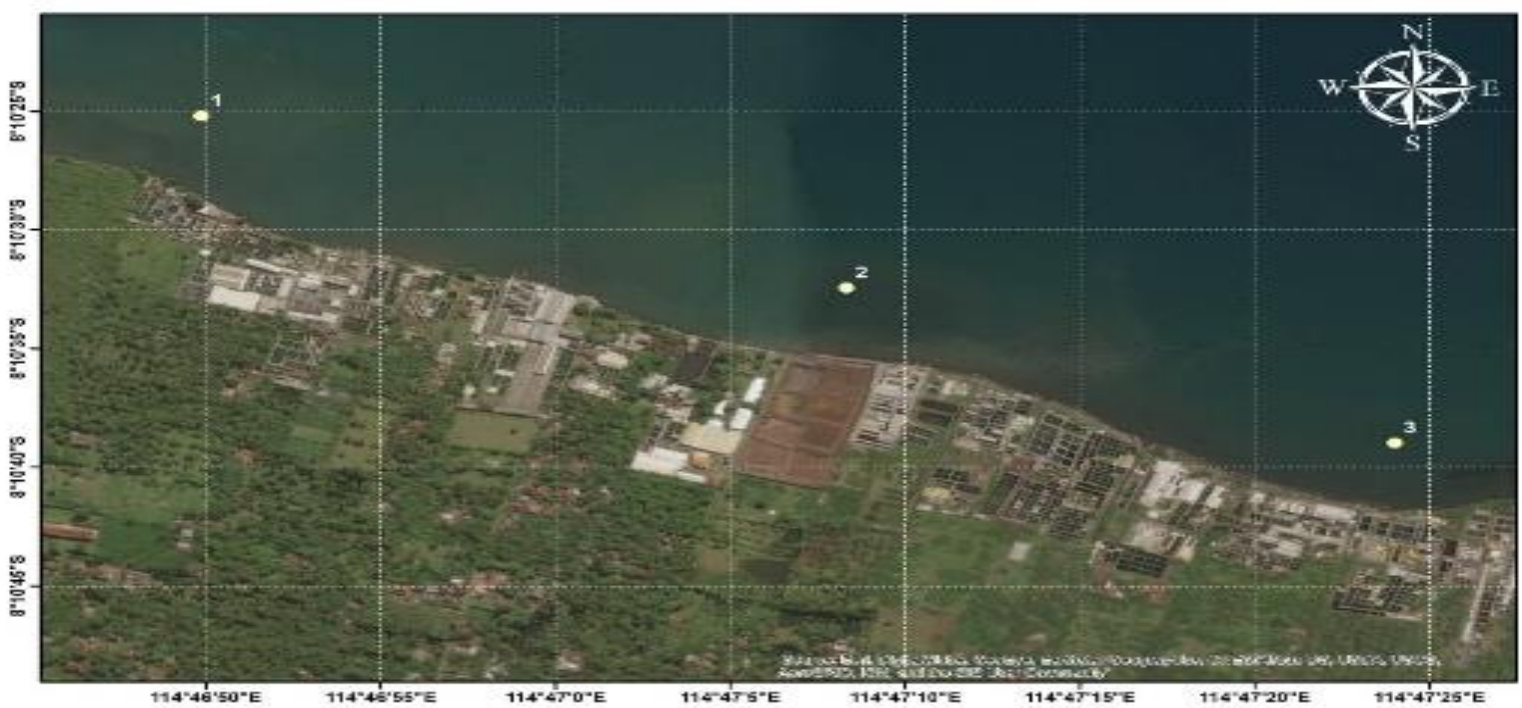

Gambar 4.

Stasiun Penelitian 3 (Desa Gerokgak). Nomer 1, 2, dan 3 adalah titik-titik dimana sempel akan diambil. 


\subsection{Variabel Penelitian}

Variabel penelitian yang diukur dalam penelitian ini adalah kualitas air. struktur komunitas fitoplankton dan produktivitas primer fitoplankton. Variabel kualitas air, yang diamati berupa kondisi fisik, kimia dan biologi perairan. Faktor fisika meliputi pengukuran suhu air $\left({ }^{\circ} \mathrm{C}\right)$, kecerahan $(\mathrm{cm})$ dan kekeruhan (ppm). Faktor kimia kualitas perairan yang diamati adalah: salisitas (\%), $\mathrm{pH}$, DO (mg/1), Nitrat/N-NO3 (mg/1), dan Fosfat P-PO4 (mg/1). Parameter biologi kualitas air meliputi jumlah jenis dan kemelimpahan plankton. Struktur komunitas fitoplankton yang diamati antara lain adalah indeks keanekaragaman $(\mathrm{H})$, keseragaman (E) dan Indeks dominansi (D).

\subsection{Penentuan Stasiun}

Penentuan stasiun berdasarkan pada observasi lokasi penelitian. Teknik penentuan lokasi sampling dalam penelitian ini adalah dengan metode purposive sampling. Berdasarkan hasil observasi lapangan maka pengambilan sampel dilakukan pada tiga stasiun yang berbeda yaitu lokasi tambak di Desa Gerokgak (stasiun 1), Desa Patas (stasiun 2) dan Desa Sumberkima (stasiun 3). Penentuan stasiun penelitian didasarkan pada karakteristik lokasi dan secara keseluruhan terdapat 6 titik sampling. Penentuan titik sampel ditentukan dengan kreteria jumlah kegiatan pelaku usaha perikanan di satu lokasi sehingga hasil yang diperoleh dapat dijadikan pertimbangan pencemaran pencemaran lingkungan.

\subsection{Tahap pengambilan data/ pengukuran}

Pada tahap ini dilakukan pengambilan data dari variabel-variabel penelitian yaitu fitoplankton, zooplankton, kualitas air dan produktivitas primer. Pada masing-masing titik pengambilan sampel dilakukan ulangan sebanyak tiga kali, dimana antar ulangan diambil dalam interval 2 minggu. Mengingat jumlah data variabel yang diukur maka pengambilan data dilakukan dalam satu hari untuk tiga stasiun penelitian per satu kali ulangan. Agar data yang lebih representatif maka pengambilan tiap pengukuran sampel dilakukan dimulai pukul 10.00 Wita dimulai dari stasiun penelitian 1 , stasiun 2 diambil pukul 12 dan stasiun penelitian diambil pukul 3. Selama pengambilan data, seluruh kondisi lapangan dicatat pada log book.

\subsection{Analisis Data}

\subsubsection{Struktur Komunitas Fitoplankton}

Analisis kuantitatif indeks biologi fitoplankton meliputi perhitunganperhitungan keseragaman $(\mathrm{H})$, keragaman (E) Adapun rumus-rumus tersebut lebih jelas sebagai berikut:

$\mathrm{H}^{1}=\sum$ Piln Pi

$P i=\frac{n i}{N}$

Dimana:

$\mathrm{H}^{1} \quad$ = Indeks keanekaragaman jenis

ni = Jumlah individu taksa ke-i

$\mathrm{N} \quad=$ Jumlah total individu

$\mathrm{i} \quad=$ Populasi spesies ke-i

\section{HASIL DAN PEMBAHASAN}

\subsection{Kualitas Perairan di Kecamatan Gerokgak}

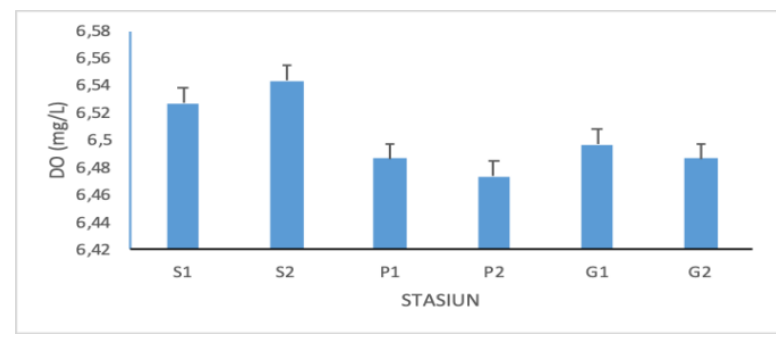

Gambar 5.

Oksigen Terlarut (DO) dari masing-masing stasiun (S1: Sumberkima Minggu 1, S2:

Sumberkima Minggu 2, P1: Patas Minggu 1, P2: Patas Minggu 2, G1: Gerokgak Minggu 1, G2: Gerokgak Minggu 2).

Secara umum kualitas perairan pantai Kecamatan Gerokgak baik. Kandungan Oksigen Terlarut (DO) berbeda antar stasiun dan waktu. Secara keseluruhan oksigen terlarut di perairan Sumberkima (S) lebih 
tinggi dibandingkan dengan Patas $(\mathrm{P})$ dan Gerokgak $(\mathrm{G})$. Oksigen terlarut di perairan Sumberkima pada stasiun satu (S1) minggu ke-1 lebih rendah $(6,53 \mathrm{ppm} \pm 0,01 \mathrm{ppm})$ dibandingkan dengan oksigen terlarut pada stasiun dua (S2) minggu ke-2 (6,54 ppm $\pm 0,01 \mathrm{ppm})$. Kandungan oksigen terlarut di perairan Patas dan Gerokgak tidak jauh berbeda antara stasiun satu minggu ke-1 dan stasiun dua minggu ke-2.

Pada stasiun satu (P1) minggu ke-1, rata-rata oksigen terlarut di perairan Patas adalah 6,5 ppm $\pm 0,02 \mathrm{ppm}$ dan stasiun dua (P2) minggu ke-2 adalah 6,47 ppm $\pm 0,02$ ppm, sedangkan oksigen terlarut di perairan Gerokgak pada stasiun satu (G1) minggu ke1 adalah 6,50ppm $\pm 0,01 \mathrm{ppm}$ dan pada stasiun dua (G2) minggu ke-2 adalah 6,5 ppm $\pm 0,01 \mathrm{ppm}$.

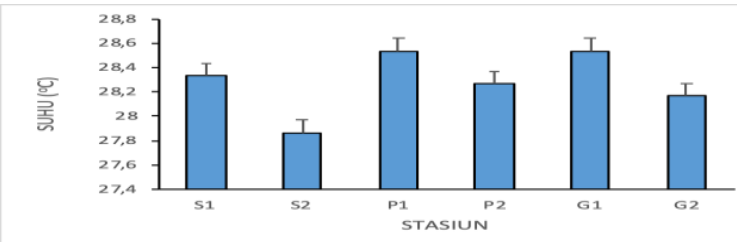

Gambar 6.

Suhu dari masing-masing stasiun (S1:

Sumberkima Minggu 1, S2: Sumberkima Minggu 2, P1: Patas Minggu 1, P2: Patas Minggu 2, G1: Gerokgak Minggu 1, G2:

Gerokgak Minggu 2).

Hasil pengambilan sempel parameter fisika berupa suhu di perairan pantai Kecamatan Gerokgak tinggi. Tingkat suhu yang diukur berbeda antar stasiun dan waktu. Secara keseluruhan suhu yang diukur di perairan Sumberkima (S) lebih rendah dibandingkan dengan tingkat suhu di perairan Patas (P) dan Gerokgak (G) seperti yang terlihat pada Gambar 6. Tingkat suhu di perairan Sumberkima (S), pada stasiun satu (S1) minggu ke-1 adalah $28,33^{\mathrm{O}} \mathrm{C} \pm 0,06^{\mathrm{O}} \mathrm{C}$ dan stasiun dua (S2) minggu ke-2 adalah $27,87^{\circ} \mathrm{C} \pm 0,058^{\mathrm{O}} \mathrm{C}$, sedangkan suhu di perairan Patas $(\mathrm{P})$ dan Gerokgak (G) di stasiun satu minggu ke-1 dan stasiun dua minggu ke-2 tidak jauh berbeda.
Tingkat suhu di perairan Patas (P) pada stasiun satu $(\mathrm{P} 1)$ minggu ke-1 suhunya lebih tinggi $\left(28,5^{\circ} \mathrm{C} \pm 0,1{ }^{\circ} \mathrm{C}\right)$ dibandingkan dengan suhu di stasiun dua (P2) minggu ke-2 $\left(28,2^{\mathrm{O}} \mathrm{C} \pm 0,2^{\mathrm{O}} \mathrm{C}\right)$, sedangkan tingkat suhu di perairan Gerokgak (G) pada stasiun satu (G1) minggu ke-1 suhunya adalah $28,53^{\mathrm{O}} \mathrm{C}$ $\pm 0,2^{\circ} \mathrm{C}$ dan stasiun dua $(\mathrm{G} 2)$ minggu ke-2 adalah $28,1^{\mathrm{O}} \mathrm{C} \pm 0,05^{\circ} \mathrm{C}$.

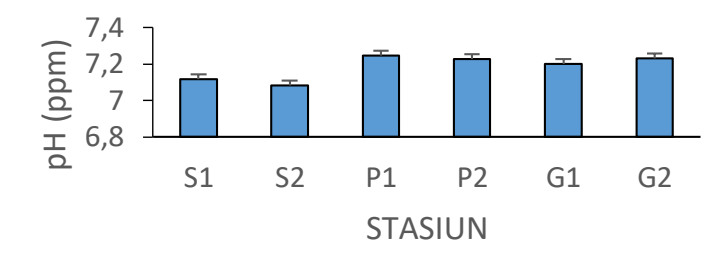

Gambar 7.

$\mathrm{pH}$ dari masing-masing stasiun (S1:

Sumberkima Minggu 1, S2: Sumberkima

Minggu 2, P1: Patas Minggu 1, P2: Patas

Minggu 2, G1: Gerokgak Minggu 1, G2:

Gerokgak Minggu 2).

Secara umum parameter kimia kandungan $\mathrm{pH}$ yang diukur di perairan pantai Kecamatan Gerokgak tinggi. Kandungan $\mathrm{pH}$ yang diukur berbeda antar stasiun dan waktu. Secara keseluruhan kandungan $\mathrm{pH}$ yang diukur di perairan Sumberkima (S) lebih rendah dibandingkan dengan kandungan $\mathrm{pH}$ di perairan Patas $(\mathrm{P})$ dan Gerokgak (G) seperti yang terlihat pada Gambar 7. Kandungan $\mathrm{pH}$ di perairan Sumberkima (S), pada stasiun satu (S1) minggu ke-1 lebih tinggi $(7,1 \pm 0,03)$ dibandingkan dengan stasiun dua (S2) minggu ke-2 $(7,08 \pm 0,03)$, sedangkan kandungan $\mathrm{pH}$ di perairan Patas $(\mathrm{P})$ dan Gerokgak (G) pada stasiun satu minggu ke-1 dan stasiun dua minggu ke-2 tidak jauh berbeda.

Di perairan Patas $(\mathrm{P})$, kandungan $\mathrm{pH}$ pada stasiun satu $(\mathrm{P} 1)$ minggu ke-1 adalah $7,2 \pm 0,05$ dan stasiun dua (P2) minggu ke-2 adalah 7,2 $\pm 0,04$, sedangkan kandungan $\mathrm{pH}$ di perairan Gerokgak $(\mathrm{G})$, pada stasiun satu (G1) minggu ke-1 adalah 7,2 $\pm 0,11$ dan stasiun dua (G2) minggu ke-2 adalah 7,2 $\pm 0,1$. 


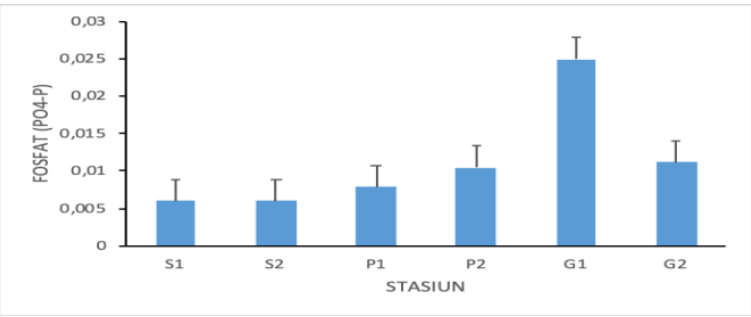

Gambar 8 .

Fosfat (PO4) dari masing-masing stasiun

(S1: Sumberkima Minggu 1, S2:

Sumberkima Minggu 2, P1: Patas Minggu 1, P2: Patas Minggu 2, G1: Gerokgak Minggu 1, G2: Gerokgak Minggu 2).

Secara umum parameter kimia kandungan Fosfat (PO4) yang diukur di perairan pantai Kecamatan Gerokgak rendah. Kandungan fosfat yang diukur berbeda antar stasiun dan waktu. Secara keseluruhan kandungan fosfat di perairan Sumberkima (S) lebih rendah dibandingkan dengan kandungan fosfat di perairan Patas $(\mathrm{P})$ dan Gerokgak (G) seperti yang terlihat pada Gambar 8.

Kandungan fosfat di perairan Sumberkima (S) pada stasiun satu (S1) minggu ke-1 sama rendahnya dengan stasiun dua (S2) minggu ke-2 yaitu 0,01 ppm $\pm 0,0$ ppm, hal ini berbeda halnya dengan kandungan fosfat di perairan Gerokgak (G) dan perairan Patas (P) pada stasiun satu minggu ke-1 dan stasiun dua minggu ke-2. Pada stasiun satu (P1) minggu ke-1, kandungan fosfat di perairan Patas (P) adalah $0,01 \mathrm{ppm} \pm 0,0 \mathrm{ppm}$ dan stasiun dua (P2) minggu ke-2 adalah 0,01ppm $\pm 0,0 \mathrm{ppm}$, sedangkan kandungan fosfat di perairan Gerokgak (G), pada stasiun satu (G1) minggu ke-1 adalah 0,06ppm $\pm 0,03 \mathrm{ppm}$ dan stasiun dua (G2) minggu ke-2 adalah $0,01 \mathrm{ppm} \pm 0,01 \mathrm{ppm}$.

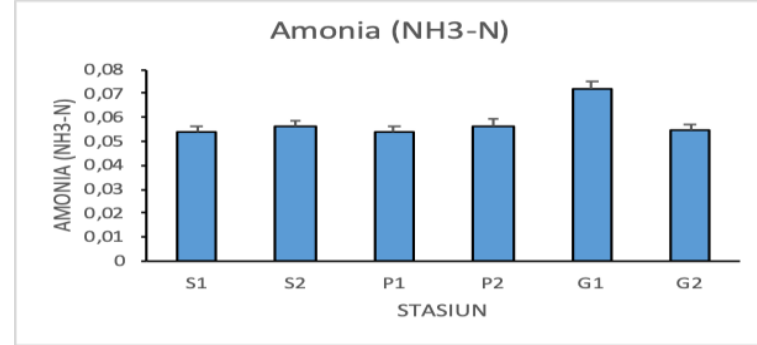

Gambar 9.

Amonia (NH3) dari masing-masing stasiun

(S1: Sumberkima Minggu 1, S2:

Sumberkima Minggu 2, P1: Patas Minggu 1, P2: Patas Minggu 2, G1: Gerokgak Minggu 1, G2: Gerokgak Minggu 2).

Secara umum parameter kimia kandungan Amonia (NH3) yang diukur di perairan pantai Kecamatan Gerokgak rendah. Kandungan amonia yang diukur berbeda antar stasiun dan waktu. Secara keseluruhan kandungan amonia di perairan Gerokgak (G) lebih tinggi dibandingkan dengan kandungan amonia di perairan Patas (P) dan Sumberkima (S) seperti yang terlihat pada Gambar 9.

Kandungan amonia di perairan Sumberkima (S) pada stasiun satu (S1) minggu ke-1 adalah 0,05ppm $\pm 0,0 \mathrm{ppm}$ dan stasiun dua (S2) minggu ke-2 adalah $0,06 \mathrm{ppm} \pm 0,0 \mathrm{ppm}$, hal ini tidak jauh beda dengan kandungan amonia di perairan Patas (P) pada stasiun satu (P1) minggu ke-1 adalah $0,05 \mathrm{ppm} \pm 0,00 \mathrm{ppm}$ dan stasiun dua (P2) minggu ke-2 adalah 0,06ppm $\pm, 0,0 \mathrm{ppm}$. Kandungan amonia di perairan Gerokgak (G) pada stasiun satu (G1) minggu ke-1 adalah $0,07 \mathrm{ppm} \pm 0,02 \mathrm{ppm}$ lebih tinggi bila dibandingkan dengan kandungan amonia pada stasiun dua (G2) minggu ke-2 yaitu sebesar $0,05 \mathrm{ppm} \pm 0,0 \mathrm{ppm}$. 


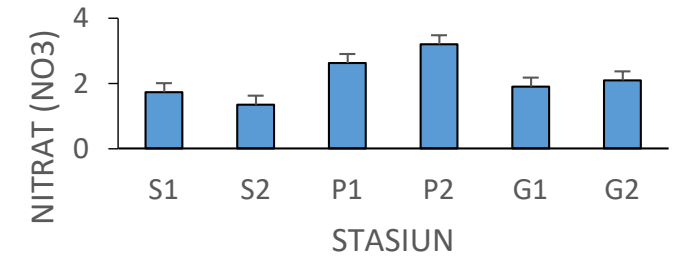

Gambar 10.

Nitrat (NO3) dari masing-masing stasiun

(S1: Sumberkima Minggu 1, S2:

Sumberkima Minggu 2, P1: Patas Minggu 1, P2: Patas Minggu 2, G1: Gerokgak Minggu 1, G2: Gerokgak Minggu 2).

Secara umum parameter kimia kandungan Nitrat (NO3) yang diukur di perairan pantai Kecamatan Gerokgak baik. Kandungan nitrat yang diukur berbeda antar stasiun dan waktu. Secara keseluruhan kandungan nitrat di perairan Patas $(\mathrm{P})$ lebih tinggi dibandingkan dengan kandungan nitrat di perairan Gerokgak (G) dan Sumberkima (S) seperti yang terlihat pada Gambar 10.

Kandungan nitrat di perairan Sumberkima (S) pada stasiun satu (S1) minggu ke-1 adalah 1,7ppm $\pm 1,97$ ppm lebih tinggi dibandingkan dengan kandungan nitrat pada stasiun dua (S2) minggu ke-2 yaitu sebesar $1,35 \mathrm{ppm} \pm, 0,78 \mathrm{ppm}$,

hal ini tidak jauh beda dengan kandungan nitrat di perairan Gerokgak (G) pada stasiun satu (G1) minggu ke-1 kandungan nitratnya adalah 1,9ppm $\pm 1,18$ ppm dan pada stasiun dua (G2) minggu ke-2 adalah 2,10ppm $\pm 0,4 \mathrm{ppm}$. kandungan nitrat di perairan Patas $(\mathrm{P})$ pada stasiun satu (P1) minggu ke-1 adalah 2,6ppm $\pm 1,78$ ppm dan pada stasiun dua (P2) minggu ke-2 yaitu sebesar 3,2ppm $\pm 0,7 \mathrm{ppm}$.

Tabel 1. Kelimpahan Fitoplankton di Perairan Sekitar Kecamatan Gerokgak.

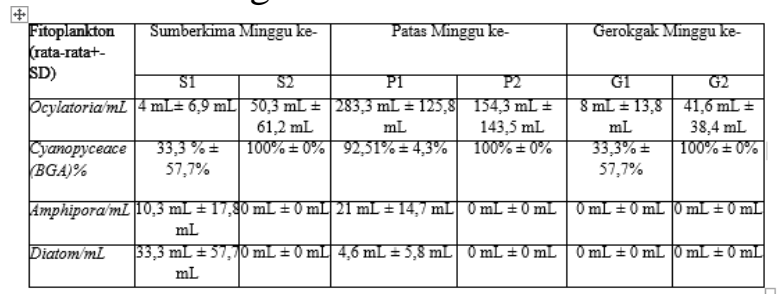

Sumber : Diolah dari data primer
Pada Tabel 1 kelimpahan fitoplankton di Kecamatan Gerokgak secara keseluruhan menunjukkan di Desa Patas mempunyai kelimpahan tertinggi Ocylatoria pada minggu $1(\mathrm{P} 1)$ yaitu $283,33 \mathrm{~mL} \pm 125,8$ $\mathrm{mL}$ dan minggu 2 (P2) yaitu $154,3 \mathrm{~mL} \pm 143,5 \mathrm{~mL}$ sedangkan untuk kelimpahan terendah ada pada Desa Sumberkima minggu 1 (S1) yaitu $4 \mathrm{~mL} \pm 6,9 \mathrm{~mL}$ dan Desa Gerokgak minggu 1 (G1) yaitu $8 \mathrm{~mL} \pm 13,8 \mathrm{~mL}$. Untuk kelimpahan Cyanopyceae pada perairan Kecamatan Gerokgak yang tertinggi ada pada Desa Patas minggu 1 (P1) yaitu 92,51\% $\pm 4,38 \%$, sedangkan pada kelimpahan tertinggi yaitu pada Desa Sumberkima minggu 2 (S2) dan Desa Gerokgak minggu 2 (G2) dengan kelimpahan Cyanopyceae masing-masing adalah $100 \% \pm 0 \%$.

Nilai kelimpahan Amphipora dan diatom tidak terlalu banyak ditemui di perairan Kecamatan Gerokgak. Untuk kelimpahan Amphipora tertinggi ada pada Desa Sumberkima minggu 1 (S1) yaitu $10,3 \mathrm{~mL} \pm 17,8 \mathrm{~mL}$ dan kelimpahan diatom yang didapat di perairan Kecamatan Gerokgak dengan nilai tertinggi ada pada Desa Sumberkima minggu 1 (S1) dengan kelimpahan 33,3mL $\pm 57,7 \mathrm{~mL}$, untuk di stasiun yang lainnya memiliki nilai $0 \mathrm{~mL}$ dikarenakan di stasiun tersebut tidak ditemukan kelimpahan-kelimpahan Amphipora maupun Diatom.

\section{SIMPULAN DAN SARAN}

\subsection{Simpulan}

Berdasarkan hasil penelitian terhadap studi kualitas air di Kecamatan Gerokgak, maka dapat disimpulkan antara lain:

1. Secara umum hasil penelitian ini menunjukkan kualitas perairan di Kecamatan Gerokgak kurang baik, kecuali perairan di sekitar Desa Sumberkima. Kualitas perairan Desa Sumberkima lebih baik dibandingkan perairan Desa Gerokgak dan perairan Desa Patas. Dapat dilihat dari hasil penelitian ini menunjukkan bahwa 
Desa Sumberkima memiliki DO lebih tinggi dan $\mathrm{pH}$ lebih rendah dibandingkan Desa Gerokgak dan Desa Patas sehingga Keanekaragaman spesies cenderung rendah dalam ekosistem yang mengalami tekanan secara fisika dan kimia dan dapat menyebabkan keanekaragaman atau ekosistem diperairan kurang baik (Oktavia, 2015)

2. Kelimpahan plankton di perairan Desa Sumberkima rendah, sedangkan kelimpahan plankton tertinggi di perairan Desa Patas dan terendah di perairan Desa Gerokgak. Jenis plankton yang dominan adalah cyanophyceae (alga biru-hijau). Menurut Nirmalasari 2018, Cyanophyceae atau ganggang hijau biru (Blue Green Alga/BGA) merupakan fitoplankton yang bersifat prokariotik. Bentuk sel Cyanophyceae umumnya berupa sel tunggal, koloni atau filamen. Dalam bentuk koloni atau filamen alga ini mampu melakukan proses fiksasi nitrogen sehingga dapat menyebabkan ledakan populasi blooming baik diperairan tawar maupun perairan laut sehingga dapat mempengaruhi ekosistem yang ada diperairan tersebut.

3. Di Desa Sumberkima oksigen terlarut di perairan tinggi dibandingkan desa Patas dan Desa Gerokgak tetapi DO yang ada di Desa Sumberkima lebih rendah dibandingkan desa lainnya sehingga kondisi perairan yang ada di Desa Sumberkima lebih baik dibandingkan Desa Patas dan Desa Gerokgak.

Menurut (Christina, 2014), tinggi rendahnya DO sangat mempengaruhi kesuburan perairan oksigen juga menentukan aktivitas biologis yang dilakukan oleh organisme aerobik atau anaerobik. Dalam kondisi aerobik, peranan oksigen adalah untuk mengoksidasi bahan organik dan anorganik dengan hasil akhirnya adalah nutrien yang pada akhirnya dapat memberikan kesuburan perairan. Dalam kondisi anaerobik, oksigen yang dihasilkan akan mereduksi senyawa- senyawa kimia menjadi lebih sederhana dalam bentuk nutrien dan gas.

\subsection{Saran}

Berdasarkan hasil penelitian terhadap studi kualitas air di Kecamatan Gerokgak, maka dapat disimpulkan saran yang bisa di pertimbangkan:

1. Bagi masyarakat dan pengusaha di Kecamatan Gerokgak harus memperhatikan pengelolaan limbahlimbah yang dihasilkan dari usaha perikanan dan khusus untuk pengusaha harus ada ijin usaha dan pengelolaan limbah agar lingkungan perairan di Kecamatan Gerokgak kualitasnya tetap terbaga.

2. Bagi pemerintah dan intansi terkait dibutuhkan dukungan, baik secara materil maupun sosialisasi terhadap pentingnya menjaga lingkungan yang ada di perairan Kecamatan Gerokgak dan mengawasi dan memberi sanksi terhadap pengusaha yang tidak mengikuti prosedur dengan membuang limbah ke lingkungan secara berlebihan yang dapat merusak kualitas perairan di Kecamatan Gerokgak,

3. Diperlukannya adanya penelitian mengenai jumlah buangan limbah usaha perikanan di Kecamatan Gerokgak yang dapat mempengaruhi ekosistem di lingkungan perairan.

\section{DAFTAR PUSTAKA}

Biggs, J.B. 2015. Educational Psychology, 2005. Learning Approaches: Examination Type, Discipline of Study, and Gender. 
Marindro. 2011. Frekuensi Pemberian Pakan Buatan Secara Optimal Pada Budidaya Udang Windu. Andi: Yogyakarta.

Nontji, Anugerah, 2015. Laut Nusantara. Cetakan Keempat. Djambatan. Jakarta.

Raswin, Muhammad. 2013. Pembesaran ikan Bandeng, Modul Pengelolaan Air Tambak. Pdf. http://zonaikan.wordpress.com/2013/10 /06/ kualitas-air-tambak-bandeng.html. 